\title{
Effect of Self Care Management Program Regarding Fatigue Among Adolescents' Cancer Patients
}

\author{
Eman N. Ramadan ${ }^{1}$, Shimmaa M. Moustafa ${ }^{2}$, Ebtisam M. Abd El aal ${ }^{1}$ \\ ${ }^{1}$ Community Health Nursing, Faculty of Nursing, Benha University. Benha, Egypt \\ ${ }^{2}$ Pediatric Nursing, Faculty of Nursing, Zigzag University, Zigzag, Egypt \\ Email address: \\ dremannabil@yahoo.com (E. N. Ramadan),Ebtisam_rohayem@yahoo.com (E. M. A. El aal)
}

\section{To cite this article:}

Eman N. Ramadan, Shimmaa M. Moustafa, Ebtisam M. Abd El aal. Effect of Self Care Management Program Regarding Fatigue Among Adolescents' Cancer Patients. American Journal of Nursing Science. Vol. 4, No. 3, 2015, pp. 101-106. doi: 10.11648/j.ajns.20150403.18

\begin{abstract}
Fatigue is a common and complex, subjective symptom with physical, emotional and cognitive dimensions. The aim of the study is to evaluate the effect of self-care management program regarding fatigue among adolescents' cancer patients. Research design Quasi-experimental design was used to complete this study. Setting: The study was conducted at the Outpatient Unit at Specialized Children Hospital in Kalyobia Governorate, and Cancer Institute in Cairo City. Sample: Simple random sample of forty six adolescents' patients with cancer who were newly or old diagnosed with cancer. Tools: Two tools were used to collect the study data: I): An interviewing Questionnaire which includes five parts: a): A study subjects' characteristics. b): Burden of the disease on patients. c): Present medical history of the study subject. d): Adolescents' patients' knowledge regarding fatigue. e): Self-care practices as reported regarding fatigue. II): Multidimensional assessment of fatigue $(M A F)$ scale which includes 12 questions -after modifying- ranged from no fatigue to sever felling with fatigue. Results: 65.2\% aged less than 14 years as the same percentage were female while $63.0 \%$ engaged in secondary education and 54.3 living in urban areas. $43.5 \%$ of study subjects had dependent on other persons for daily living activities, $69.6 \%$ having no any sports. Overall the results have statistically significant differences before and after implementing the program regarding (MAF) scale. Conclusion: the study concluded that the adolescent patient with cancer had inadequate knowledge regarding fatigue, and the health educational program was succeed to increasing their knowledge, and improving health practices to deal with fatigue, their overall activities were improved after implementation the program regarding MAF scale. Recommendations: The study recommended that the importance of health educational program for patients and families regarding self care management of fatigue related cancer should be provided.
\end{abstract}

Keywords: Adolescent, Cancer Patients, Self Care, Fatigue

\section{Introduction}

Self-care is the control of one's own care for the purposes of health, the person being able to decide how and what action needed to be taken and by whom, in order to sustain his/her care/treatment, and it is the activity that individuals are being involved in, finding effective ways to deal with their identified problems and enable them to achieve their goals $^{(1)}$.

Self-care becomes an integral part of an effective and efficient health care system, and self-management includes the strategies which individuals utilize to enhance control and maximize well-being ${ }^{(2)}$. Patients may engage in self-care activities, such as napping, sleeping longer, distracting themselves, or conserving energy by simplifying their $\operatorname{activities}^{(3)}$.

Cancer related fatigue is a multifaceted condition characterized by diminished energy and an increased need to rest disproportionate to any recent change in activity level. It is accompanied by other clinical characteristics, including generalized weakness, diminished mental concentration, insomnia or hypersomnia, and emotional reactivity. Decrements in physical, social, cognitive, and vocational functioning, adverse mood changes, sleep disturbances, treatment noncompliance, and emotional and spiritual distress for both patients and their family members ${ }^{(4)}$.

Adolescents defined cancer related fatigue as "a complex changing state of exhaustion that at times seems to be a 
physical condition, at other times a mental state and still other times to be a combination of physical and mental tiredness ${ }^{(5)}$. It is also an unusual, unpleasant feeling of tiredness or exhaustion with physical, cognitive, affective, and spiritual dimensions appearing in varying patterns, often causing distress and irritation and affecting self-esteem ${ }^{(3)}$.

The etiology of fatigue is not yet clear, the range and effectiveness of interventions are limited. Besides the treatment of contributing factors such as anemia, depression and other comorbidities, the strongest evidence supports enhanced activity and psychosocial interventions, but some evidence also backs attention-restoring therapy, nutrition counseling and sleep therapy ${ }^{(3)}$.

The adolescents become able to understand their symptoms on a more advanced level and to articulate their symptom experience more clearly, they developing a sense of personal identity as well as a sense of their role in the world and They are achieving independence from parents and making significant decisions related to education, careers, and relationships as they approach adulthood ${ }^{(6)}$.

In Egypt, a large uncertainty accompanies statistics for cancer incidence and survival, 18496 new cancer cases with confirmed and registered malignancy at the National Cancer Institute in Egypt between January 2002 and December 2003, $1937(10.5 \%)$ were children under the age of 20 years. According to Children's Cancer Hospital, 8500 children are estimated to be diagnosed with cancer in Egypt every year. The new Children's Cancer Hospital had 1862 admitted cases during 2008, which approximately account for onefourth of all children diagnosed with cancer in Egypt $2008^{(7)}$.

Nurses should be focused on the ability of patients to perform self-care, and the practices of activities that individuals initiate and perform on their own behalf in maintaining life, health and well-being. Gathering information about common symptoms and monitoring the success of self-reported strategies can guide nurses in helping patients optimally during treatments for cancer. The goal of nursing is to promote the development of self-care in clients, and must be able to use and guide patients to use it ${ }^{(8)}$.

\section{Aim of the Study}

The study aimed to evaluate the effect of self-care management program for adolescents' patients with cancer regarding fatigue, through:

1. Identifying the adolescents knowledge and practices regarding cancer related fatigue

2. Measuring the degree of fatigue according Multidimensional assessment of fatigue (MAF) scale

3. Designing and implementing self-care management program

4. Evaluate the effect of self care management program.

\section{Research Hypothesis}

Self care management program will be improved the patients' knowledge and practices regarding fatigue

\section{Subject and Methods}

\subsection{Research Design}

Quasi-experimental design was used to complete this study

\subsection{Setting}

The study was conducted at the outpatient Unit at specialized children Hospital in Kalyobia Governorate, and cancer institute in Cairo; the study subjects were followed by conducting visits to them at their homes. The researchers provided them health education program about self-care management regarding fatigue.

\subsection{Sample}

Simple random sample of 46 Aadolescent patient with cancer "6 from specialized children Hospital and 40 from cancer institute" who were newly or old diagnosed with cancer and fulfilled the following criteria aged from 13-18 years, Cancer treatment including chemotherapy and /or radiation and surgery and free from any other chronic disease.

Research instrument (tools): two tools were used to collect the study data:

I - An interviewing Questionnaire: It was developed by the researchers and includes five parts to collect data about: a) A study subjects' socio-demographic characteristics as age, gender, education level, residence, occupation and income. b) Burden of the disease on patients as dependency, sports, supportive person, most time for feeling fatigue, feeling fatigue last week. c) Medical history of the study subject as type of disease, type of treatment, treatment period. d): Adolescent patients' knowledge regarding fatigue as meaning of fatigue, signs and symptoms, causes, precaution to avoid fatigue, factors aggravating fatigue, and factors relieving fatigue. e): Patients' self-care practices as reported regarding fatigue as going to sleep early, getting up later, getting naps, making sports a lot, getting fresh air, taking large amount of tea and café, and put a plan of daily living activities.

Scoring system for patients' knowledge

The adolescents patients' knowledge was calculated for each item as follows: Complete and /or correct answer was scored (2), Incomplete correct answer was scored (1), while don't know or wrong answer was scored (0).

Scoring system for patients' self-care practices as reported

The adolescents patients' practices was calculated for each item as follows: done practices was scored (1) and not done was scored (0).

II- Multidimensional assessment of fatigue (MAF) scale. which includes 12 questions -after modifying- about how severe is the fatigue which you have been experiencing, to what degree has fatigue caused you distress, do household chores, cook, bath or wash, dress, work, visit or socialize with friends or family, engage in leisure and recreational activities, shop and do errands, walk, and Exercise other than walking.

Scoring system

The MAF scale was calculated as mean and standard 
division; ranged from no fatigue to sever feeling with fatigue with scoring from one to ten.

Content Validity: Content validity was done through five experts from Faculty Members of Community Health Nursing Department.

Ethical consideration: All relevant ethical aspects were considered for ensuring the confidentiality of the collected data through; gaining oral consent for participation in the study, explaining the purpose of the study, right to refuse to continue participation at any time without giving any reasons

Pilot study: was carried out on ten cancer patients to assess the tool clarity, applicability, and time needed to fill each sheet. The pilot study was excluded from the main study sample.

\subsection{Field Work}

- Preparation of data collection was carried out from the beginning of August 2014 to the end of September 2014 and data collection from beginning of October 2014 to end of December 2014.

- An official letter was issued from the Dean of the Faculty of Nursing to the director of Specialized Children Hospital and Cancer Institute including the aim of the study.

- Approval was taken from the director of outpatient units and oral consent from each cancer patient and their caregiver to conduct the study.

- Explanation of the purpose of the research was done to the cancer patient and their caregiver in order to gain their cooperation.

- The researchers conducted the program twice/week (Saturdays and Thursdays), from 10.00 a.m. to 12.00 p.m.

- Each patient was interviewed individually by the researcher to fill out the sheet.

Health educational program construction:

The program was conducted at four phases:

1- Preparatory phase: A review of recent, current, national and international literature in various aspects regarding fatigue about cancer patient. The tools questionnaire was designed to assess self-care management of patient with cancer regarding fatigue before and after implementing the program.

2- The assessment phase: The pre test questionnaire was designed and implemented to identify self-care management of patient with cancer regarding fatigue as knowledge about fatigue and their self-care management and multideminational scale for fatigue to decrease level of fatigue sensation.

3- The planning and implementing phase:

The self-care management program was designed, with general objective was to evaluate the effect of self-care management program for adolescents with cancer regarding fatigue

The program content included:

- Knowledge related fatigue as meaning of fatigue, signs and symptoms, causes, precaution to avoid fatigue, factors aggravating fatigue, and factors relieving fatigue.

- Self-care practices to improve health and decrease fatigue level

The program includes three sessions for self-care management of fatigue.

Each session takes from 20-30 minutes.

At the end of the program implemented, a booklet of the program was given to each adolescent patient as a reference.

A post test was done to evaluate the effect of the health program on improving the adolescent patient self-care management regarding fatigue.

The teaching methods used were discussions, brainstorming, and lecture.

\section{The fourth: Evaluating phase}

To evaluate the effect of the self-care management of adolescent cancer patient knowledge and self-care management regarding fatigue through using post test that similar to the pre test was applied.

\section{Results}

Table (1): showed that $65.2 \%$ aged less than 14 years as the same percentage were female while $63.0 \%$ engaged in secondary education and $54.3 \%$ living in urban areas.

Table (1). Frequency distribution of studied patients regarding sociodemographic characteristics $(n=46)$.

\begin{tabular}{lll}
\hline Socio-demographic characteristics & No & \% \\
\hline Age & 30 & 65.2 \\
$10-14$ & 16 & 34.8 \\
$14-18$ & $12.97 \pm 2.5$ & \\
Mean \pm SD & & \\
Sex & 16 & 34.8 \\
Male & 30 & 65.2 \\
Female & & \\
Educational level & 13 & 28.3 \\
Basic education & 29 & 63.0 \\
Secondary & 4 & 8.7 \\
High education & & \\
Residence & 25 & 54.3 \\
Urban & 21 & 45.7 \\
Rural & & \\
\hline
\end{tabular}

Table (2): described that $43.5 \%$ of study sample had dependent on other persons for daily living activities, $69.6 \%$ having no any sports, while all of them says parents who supported them during treatment, and the most time they feeling fatigue were after making activity

Table (3): clarified that $39.1 \%$ suffering from leukemia, $52.2 \%$ of them treated by chemotherapy, $43.5 \%$ of them treated from three to six months, and 86.9 of them suffering fatigue every day. 
Table (2). Frequency distribution of studied patients regarding burden of disease $(n=46)$.

\begin{tabular}{lll}
\hline Effect of disease & No & \% \\
\hline Dependency & & \\
Independent & 5 & 10.9 \\
Needs helper & 21 & 45.7 \\
Dependent & 20 & 43.5 \\
Sports & & \\
Weekly & 8 & 17.4 \\
More than once weekly & 6 & 13.0 \\
No sport & 32 & 69.6 \\
Supportive person & & \\
Parents & 46 & 100.0 \\
Friends & 12 & 5.5 \\
School collage & 30 & 13.8 \\
Other diseased persons & 18 & 8.3 \\
Most time for feeling fatigue & & \\
In the morning & 30 & 13.8 \\
All the day & 30 & 13.8 \\
In the evening & 25 & 11.5 \\
After making activity & 46 & 100.0 \\
Feeling fatigue last week & & \\
Every day & 40 & 86.9 \\
Most of time & 36 & 78.3 \\
Rarely & 20 & 43.5 \\
No felling fatigue & 4 & 8.6 \\
\hline
\end{tabular}

Table (3). Frequency distribution of studied patients regarding present history $(n=46)$.

\begin{tabular}{lll}
\hline Present illness & No & \% \\
\hline Type of disease & 18 & 39.1 \\
Leukemia & 11 & 23.9 \\
Lymphoid tissue tumors & 8 & 17.4 \\
Bone, epithelial \&soft tissue & 9 & 19.6 \\
Internal organs & & \\
Type of treatment & 24 & 52.2 \\
Chemotherapy & 6 & 13.0 \\
Radiotherapy & 16 & 34.8 \\
Surgical & & \\
Treatment period & 16 & 34.8 \\
Less than three month & 20 & 43.5 \\
From three months to six & 10 & 21.7 \\
More than six months &
\end{tabular}

Table (4): showed that the adolescent patient increasing their knowledge after implementing the program, the highest increasing was observed at Meaning of fatigue $(28.3 \%)$ before the program and reach $96.6 \%$ after the program and the lowest at Signs and symptoms (21.7\%) before the program to reach $(76.1 \%)$ after the program, overall the results had statistically significance differences between before and after implementing the program regarding adolescents patients knowledge.

Table (4). Frequency distribution of studied patients regarding correct knowledge pre and post program $(n=46)$.

\begin{tabular}{|c|c|c|c|c|c|c|}
\hline \multirow{2}{*}{ Patient knowledge } & \multicolumn{2}{|l|}{ Pre } & \multicolumn{2}{|c|}{ Post } & \multirow{2}{*}{$\mathbf{X}^{2}$} & \multirow{2}{*}{$\begin{array}{l}\text { p- } \\
\text { value }\end{array}$} \\
\hline & No & $\%$ & No & $\%$ & & \\
\hline Meaning of fatigue & 13 & 28.3 & 32 & 96.6 & 15.7 & 0.000 \\
\hline Signs and symptoms & 10 & 21.7 & 35 & 76.1 & 27.1 & 0.000 \\
\hline Causes & 14 & 30.4 & 36 & 78.3 & 21.2 & 0.000 \\
\hline $\begin{array}{l}\text { Precaution to avoid } \\
\text { fatigue }\end{array}$ & 5 & 10.9 & 42 & 91.3 & 59.5 & 0.000 \\
\hline $\begin{array}{l}\text { Factors aggravating } \\
\text { fatigue }\end{array}$ & 6 & 13.0 & 37 & 80.4 & 41.9 & 0.000 \\
\hline $\begin{array}{l}\text { Factors relieving } \\
\text { fatigue }\end{array}$ & 13 & 28.3 & 37 & 80.4 & 25.2 & 0.000 \\
\hline
\end{tabular}

Table (5): described that the mean score of adolescent patient with cancer were improved after implementing the program that improvement was observed at visit or socialized with friends and families from $2.86 \pm 1.49$ before the program to $7.13 \pm 1.54$ after the program, overall the results has statistically significant differences before and after implementing the program regarding (MAF) scale.

Table (6): demonstrated that positive changes of adolescent patients with cancer regarding fatigue post program than pre program especially for going to sleep early from $32.6 \%$ pre program to $80.4 \%$ post program and put a plan of daily activity from $10.9 \%$ pre program to $95.7 \%$ post program. Overall the results have statistically significance differences pre and post program for all items.

Table (5). Comparison of mean of studied patients regarding (MAF) scale pre and post program $(n=46)$.

\begin{tabular}{|c|c|c|c|c|}
\hline \multirow{2}{*}{ Patient scale } & \multirow{2}{*}{$\begin{array}{l}\text { Pre } \\
\text { Mean } \pm \text { SD }\end{array}$} & \multirow{2}{*}{$\begin{array}{l}\text { Post } \\
\text { Mean } \pm \text { SD }\end{array}$} & \multirow[t]{2}{*}{$\mathbf{T}$} & \multirow[t]{2}{*}{ p-value } \\
\hline & & & & \\
\hline How severe is the fatigue which you have been experiencing? & $2.82 \pm 1.37$ & $7.04 \pm 1.53$ & 16.58 & .000 \\
\hline To what degree has fatigue caused you distress? & $2.52 \pm 1.37$ & $6.41 \pm 1.35$ & 14.24 & .000 \\
\hline Do household chores & $3.60 \pm 1.85$ & $6.71 \pm 1.34$ & 9.61 & .000 \\
\hline Cook & $2.97 \pm 1.58$ & $6.52 \pm 1.51$ & 11.24 & .000 \\
\hline Bath or wash & $3.17 \pm 1.96$ & $6.69 \pm 1.45$ & 9.41 & .000 \\
\hline Dress & $2.65 \pm 1.53$ & $6.63 \pm 1.71$ & 11.80 & .000 \\
\hline Visit or socialize with friends or family & $2.86 \pm 1.49$ & $7.13 \pm 1.54$ & 14.74 & .000 \\
\hline Engage in leisure and recreational activities & $2.52 \pm 1.32$ & $6.71 \pm 1.82$ & 18.26 & .000 \\
\hline Shop and do errands & $2.52 \pm 1.32$ & $6.63 \pm 1.91$ & 13.20 & .000 \\
\hline Walk & $3.15 \pm 1.61$ & $6.41 \pm 2.08$ & 8.82 & .000 \\
\hline Exercise, other than walking & $2.76 \pm 1.63$ & $6.82 \pm 1.70$ & 13.46 & .000 \\
\hline
\end{tabular}


Table (6). Frequency distribution of studied patients regarding patient self-care practices to avoid fatigue pre and post program ( $n=46)$.

\begin{tabular}{|c|c|c|c|c|c|c|c|c|c|c|}
\hline \multirow{3}{*}{ Patient self-care practices } & \multicolumn{4}{|l|}{ Pre } & \multicolumn{4}{|c|}{ Post } & \multirow{3}{*}{$X^{2}$} & \multirow{3}{*}{ p-value } \\
\hline & \multicolumn{2}{|l|}{ Yes } & \multicolumn{2}{|l|}{ No } & \multicolumn{2}{|c|}{ Yes } & \multicolumn{2}{|l|}{ No } & & \\
\hline & No & $\%$ & No & $\%$ & No & $\%$ & No & $\%$ & & \\
\hline Going to sleep early & 15 & 32.6 & 31 & 67.4 & 37 & 80.4 & 9 & 19.6 & 21.4 & 0.00 \\
\hline Getting up later & 25 & 54.3 & 21 & 45.7 & 35 & 76.1 & 11 & 23.9 & 4.49 & 0.00 \\
\hline Getting naps & 14 & 30.4 & 32 & 69.6 & 11 & 23.9 & 35 & 76.1 & .494 & .482 \\
\hline Making sports a lot & 43 & 93.5 & 3 & 6.5 & 24 & 52.2 & 22 & 47.8 & 19.8 & 0.00 \\
\hline Getting fresh air & 5 & 10.9 & 41 & 89.1 & 23 & 50.0 & 23 & 50.0 & 16.6 & 0.00 \\
\hline Taking large amount of tea and café & 13 & 28.3 & 33 & 71.7 & 38 & 82.3 & 8 & 17.4 & 27.4 & 0.00 \\
\hline Put a plan of daily living activities & 44 & 95.7 & 2 & 4.3 & 5 & 10.9 & 41 & 89.1 & 66.4 & 0.00 \\
\hline
\end{tabular}

Table (7). Percentage distribution of studied patients regarding feeling fatigue pre and post program ( $n=46)$.

\begin{tabular}{|c|c|c|c|c|c|c|c|c|}
\hline \multirow{3}{*}{ Patient scale } & \multicolumn{3}{|l|}{ Pre } & \multicolumn{3}{|l|}{ Post } & \multirow[t]{2}{*}{$\mathbf{X}^{2}$} & \multirow[t]{2}{*}{ P-value } \\
\hline & Always & Some-times & Never & Always & Some-times & Never & & \\
\hline & $\%$ & $\%$ & $\%$ & $\%$ & $\%$ & $\%$ & & \\
\hline Feeling fatigue & 39.1 & 15.2 & 45.7 & 4.3 & 34.8 & 60.9 & 17.3 & 0.00 \\
\hline Feeling tired & 41.3 & 10.9 & 47.8 & 6.5 & 19.6 & 73.9 & 15.3 & 0.00 \\
\hline Difficulties when beginning some thing & 54.3 & 15.2 & 30.4 & 10.9 & 28.3 & 60.9 & 19.8 & 0.00 \\
\hline Difficulties to end some thing & 58.7 & 19.6 & 21.7 & 2.2 & 10.9 & 87.0 & 43.2 & 0.00 \\
\hline Able to make activity & 69.6 & 26.1 & 4.3 & 32.6 & 10.9 & 56.5 & 29.6 & 0.00 \\
\hline Needs to sleep during a day & 97.8 & 2.2 & 0.0 & 2.2 & 23.9 & 73.9 & 84.4 & 0.00 \\
\hline Feeling tired during day & 65.2 & 15.2 & 19.6 & 32.6 & 45.7 & 21.7 & 12.0 & 0.00 \\
\hline Feeling fatigue during eating & 80.4 & 17.4 & 2.2 & 19.6 & 23.9 & 56.5 & 40.6 & 0.00 \\
\hline Needs helper to make activity & 80.4 & 10.9 & 8.7 & 2.2 & 23.9 & 73.9 & 60.0 & 0.00 \\
\hline Feeling depression because disease & 26.1 & 50.0 & 23.9 & 2.2 & 6.5 & 91.3 & 42.8 & 0.00 \\
\hline
\end{tabular}

Table (7): showed that the most frequency distribution of study sample regarding fatigue was improved for difficulties to end something to reach $87.0 \%$ after the program compared by $21.7 \%$ before the program followed by felling tired and needs helper to make activity $73.9 \%$ after the program compared by $47.8 \% \& 8.7 \%$ respectively before the program. Overall the results had statistically significance differences between before and post program regarding feeling fatigue.

\section{Discussion}

Fatigue is a common side-effect of cancer and its treatment and it is a distressing persistent, subjective sense of physical, emotional and/or cognitive tiredness or exhaustion related to cancer or cancer treatment that is not proportional to recent activity and interferes with usual functioning. In about one third of cancer survivors fatigue may persist for months or even years after cancer treatment. Fatigue is known as one of the most prevalent and distressing long-term consequences of cancer $^{(9)}$.

Concerning socio-demographic characteristics the present study revealed that around two thirds aged less than 14 years as the same percentage were female, and around half of cancer patients treated from three to six months, this results incongruent with Zekry etal., ${ }^{(10)}$ who reported that The disease duration ranged from 3 to 13 months (mean $\pm \mathrm{SD}=$ $7.87 \pm 2.24)$. Regarding the principal complaint of the patients, 17/30 [9 males (30\%) and 8 females (26.67\%)] presented with the complaint of fatigue. this changes may be due to differences in study subjects

Regarding the patients' needs helper the present study revealed that less than half of study sample had dependent on other persons for daily living activities, more than two thirds having no any sports, while all of them says parents who supported them during treatment, and the most time they feeling fatigue were after making activity, and majority of them suffering fatigue every day. These results in line with Spichiger' et al. ${ }^{(3)}$, who stated that lacking input from the patients, physicians fail to offer interventions; lacking information on fatigue and education for themselves and their families, affected patients report a sense that their fatigue is unrecognized and on average, fatigued patients reported selfcare actions on half of the days. This result may be due to that cancer makes a significant change in physical abilities such as playing sports or participating in activities with friends.

Regarding the most common type of cancer among studied sample clarified that more than one third suffering from leukemia, and less than half of them treated from three to six months, this result was in harmony with study conducted by Hassan ${ }^{(11)}$, who founded that the majority of children had leukemia or lymphoma. In the same context, Corner and Bailey ${ }^{(12)}$ stated that about one-third of all childhood cancers were Leukemia. This could be due to environmental factors such as duration and exposure to certain toxic chemicals that could predispose to leukemia,

According the treatment the present study revealed that around half of study sample treated by chemotherapy this in 
line with Wells ${ }^{(13)} \&$ Hassan ${ }^{(10)}$, founded that Chemotherapy was the most common type of cancer treatment for children. And American Cancer Society ${ }^{(14)}$, reported that many patients diagnosed with cancer will be treated with chemotherapy. This could reveal that the most effective treatment for all types of cancer was chemotherapy

According the patient knowledge that increasing their knowledge after implementing the program, with statistically significance differences between adolescent patients' knowledge before and after implementing the program. This results inline with Spichiger' etal. (3), who reported that Patient and family education and counseling are recommended in most cases of cancer. And Eaton, et al. ${ }^{(14)}$, who stated that there is limited information available on fatigue in children.

Regarding practices of the adolescents' patients experience to deal with fatigue the present study revealed that improved for difficulties to end something, felling tired and needs helper to make activity. This in line with Hofman et al. ${ }^{(16)}$ stated that cancer patients reported significant impairment in their ability to complete a variety of activities of daily living, including preparing food, cleaning the house, light lifting, and social activities with friends and family.

\section{Conclusion}

The study concluded that the adolescent patient with cancer had inadequate knowledge regarding fatigue, around half of them are dependent on others, and all of them the parents are most supported persons for them and the most time they feeling fatigue were after making activity. The health educational program were succeed to increasing their knowledge regarding fatigue, and improving health practices to deal with fatigue, their overall activities were improved after implementation the program regarding MAF scale. There are positive changes of adolescent patients with cancer regarding fatigue post program than pre-program. Overall there are statistically significance differences pre and post program for all items.

\section{Recommendations}

The study recommended that the importance of health educational program for patients and families regarding self care management should be provided.

Illustrated booklet should be distributed at all outpatient clinics for all cancer patients and their families regarding disease.

\section{References}

[1] Linda, F., \& Barbara, S. (2009): Nursing care an essential guide. British Library; p. 262.

[2] Johnston B., McGill, M., Milligan S., McElroy D., Foster, C., and Kearney N. (2009): Self-care and end of life care in advanced cancer: Literature review, European Journal of Oncology Nursing, 13, ( 5), Pages 386-398.

[3] Spichiger, E., Rieder E., Fröhlich C., and Kesselring A. (2012): Fatigue in patients undergoing chemotherapy, their self-care and the role of health professionals: A qualitative study, European Journal of Oncology Nursing, 16,( 2), Pages 165171

[4] Mitchell S. (2010): Cancer-Related Fatigue: State of the Science, PM\&R, 2, (5), Pages 364-383

[5] Perdikaris P., Merkouris A., Patirakic E., Tsoumakas K.,Vasilatou-Kos midis E., and Matziou V., (2009): Evaluating cancer related fatigue during treatment according to children's, adolescents' and parents' perspectives in a sample of Greek young patients, 13, (5); Pp 399-408

[6] Erickson J., MacPhers on C., Ameringer S., Baggott C.,Linder L., and Stegenga K.(2013): Symptoms and symptom clusters in adolescents receiving cancer treatment: A review of the literature, International Journal of Nursing Studies, 50, (6), P.p 847-869

[7] El Malla H,(2014): improving care of children with cancer in Egypt , Institute of Clinical Sciences, Sahlgrenska Academy at University of Gothenburg, p7

[8] Piamjariyakul U., Williams P., Prapakorn S., Kim M., Park L., Rojjanasrirata W., and Williams A. (2010): Cancer therapyrelated symptoms and self-care in Thailand, European Journal of Oncology Nursing, 14, (5), P.p 387-394.

[9] Everts F., Lee M., and Meezenbroek E. (2015): Web-based individual Mindfulness-Based Cognitive Therapy for cancerrelated fatigue - A pilot study, internet international, Available online 30 March 2015

[10] Zekry O., Ahmed M., and Abd Elwahid H. (2013): The impact of fatigue on health related quality of life in adolescents with benign joint hypermobility syndrome, The Egyptian Rheumatologist, 35, (2), Pages 77-85

[11] Hassan G. (2011): Effect of Guided Imagery relaxation Sessions versus story telling on reducing the intensity of nausea and vomiting in children undergoing chemotherapy, Master Thesis. Faculty of Nursing, Menofia University

[12] Corner J., and Bailey C. (2008): Cancer nursing in context. 2nd ed. Black well Comp, Singapore. United Kingdom. PP: $447-475,578$

[13] Wells M. (2004): The Impact of Cancer. In: Cancer Nursing Care In Context, 2nd ed. Swanton Co, Victoria. P: 62.

[14] American Cancer Society (2010): Fatigue in people with cancer, available at: www.cancer.org/fatigue-in-people-withcancer-pdf. Accessed on [May, 16, 2013].

[15] Eaton M., Hinds P., O'Neill J., Alcoser P., Bottomley S., Kline N., Euell K., Howard V., Gattuso J. (1999): Developing a conceptual model for fatigue in children, European Journal of Ontology Nursing 3(I) 5-11

[16] Hofman M, Ryan J, Figueroa- Moseley CD, Pierre J, and Morrow G, (2007): Cancer- related Fatigue: The scale of the problem. The Oncologist Journal; 12:4-10. 